\title{
Innovative and Highly Productive Joining Technologies for Multi-Material Lightweight Car Body Structures
}

\author{
G. Meschut, V. Janzen, and T. Olfermann
}

(Submitted August 16, 2013; in revised form March 8, 2014; published online April 8, 2014)

\begin{abstract}
Driven by increasing costs for energy and raw material and especially by the European $\mathrm{CO}_{2}$-emission laws, automotive industry faces the challenge to develop more lightweight and at the same time still rigid and crash-stable car bodies, that are affordable for large-scale production. The implementation of weightreduced constructions depends not only on the availability of lightweight materials and related forming technologies, but also on cost-efficient and reliable joining technologies suitable for multi-material design. This article discusses the challenges and requirements for these technologies, based on the example of joining aluminium with press-hardened boron steels, what is considered as a very important material combination for affordable future lightweight mobility. Besides a presentation of recent developments for extending the process limits of conventional mechanical joining methods, new promising technologies such as resistance element welding are introduced. In addition, the performance, advantages, and disadvantages of the presented technologies are compared and discussed.
\end{abstract}

Keywords boron steels, car body engineering, friction element welding, joining technology, lightweight design, mechanical joining, multi-material design, resistance element welding, self-pierce riveting

\section{Introduction}

All kind of European producing industries face the challenge of increasing costs for raw materials and energy as well as the European environmental legislation for greenhouse gas emissions. For strongly affected sectors like the automotive industry, the development of innovative, competitive, and energy-efficient products is crucial for the success on the global markets. Besides the development of improved or new powertrain concepts, a significant reduction of the vehicle weight is necessary to fulfill the strict European $\mathrm{CO}_{2}$ emission laws for new cars from 2015 on $(\operatorname{Ref} 1,2)$

Since the car body structure has a significant share of the total vehicle mass, weight reduction measures often focus on the implementation of various lightweight materials like advanced high-strength steels, aluminium sheet, cast and extruded profiles, or fiber-reinforced plastics into the body structure (Ref 2). The challenge is to realize a significant weight

This article is an invited submission to JMEP selected from presentations at the Symposia "Wetting," "Interface Design," and "Joining Technologies" belonging to the Topic "Joining and Interface Design" at the European Congress and Exhibition on Advanced Materials and Processes (EUROMAT 2013), held September 8-13, 2013, in Sevilla, Spain, and has been expanded from the original presentation.

G. Meschut, V. Janzen, and T. Olfermann, Laboratory for Materials and Joining Technology (LWF), University of Paderborn, Paderborn, Germany. Contact e-mail: thomas.olfermann@lwf.upb.de.

reduction while improving car body stiffness and crash performance, at reasonable costs. Therefore, an intelligent, load-oriented multi-material design is often the optimal design solution. The choice of specific materials and material combinations strongly depends on the cost target and therefore on the targeted market segment of the vehicle. In order to achieve the $\mathrm{CO}_{2}$ reduction goals in the automotive industry, it is necessary to implement affordable lightweight design also in cars with high-production volumes, like small cars and mid-class cars. Ultra-high-strength hot-stamped boron steels (UHSS) with tensile strengths of usually up to $1.650 \mathrm{MPa}$ offer a great weight reduction potential at moderate costs and therefore can be found in almost every car of European car manufacturers today (Ref 3, 4). For further weight reduction, panels made of mild steels like floor parts, roof, hood, or doors can be substituted by aluminium sheet alloy panels (see Fig. 1).

One prerequisite for multi-material structures in car bodies is the availability of material-capable and cost-efficient joining technologies (Ref 6,7). Due to the dissimilar properties of the materials in such composite designs, classic automotive highproductive welding technologies like gas metal arc welding or resistance spot welding (RSW) quickly reach their process limitations. In case of welding (uncoated) steel to aluminium, brittle intermetallic compounds are formed due to the limited solubility of the materials in solid state (Ref 7-9). Recent developments in RSW allow controlling the size of these phases by asymmetric heat input during a resistance welding process (Ref 8). Other technologies like gas metal arc welding and brazing with reduced heat input or friction-stir welding technologies are also utilized and investigated for joining steel to aluminium $(\operatorname{Ref} 8,9)$. However, these processes do not work with all coatings of $22 \mathrm{MnB} 5$ and require further improvement to reach sufficient reliability and process capability for an automotive series production environment.

Hybrid joining in terms of adhesive bonding in combination with a spot-joint, e.g., a resistance spot-weld or a clinched joint, is already state-of-the-art since several years in car body 


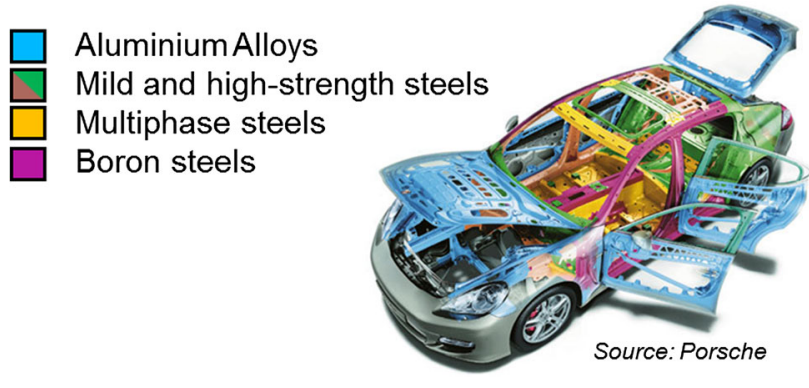

Fig. 1 Porsche 970 "Panamera" as an example of multi-material design using aluminium and boron steels (Ref 5)

manufacturing. By using heat-curing epoxy-based structural adhesives, the joint strength can be increased significantly (Ref 10). Moreover, the adhesive layer also isolates and seals the joint area, what is a very important aspect for multi-material design as the difference in electrochemical potential of the dissimilar materials can result in accelerated corrosion effects (Ref 7). Another advantage of hybrid joining is, that the disadvantages of adhesive bonding, like aging effects, poor performance under peel load, creep effects or long curing times, can be compensated by adding a spot-joint after applying the uncured adhesive.

Today, mechanical joining technologies like clinching and self-pierce riveting are established in many automotive production lines for joining multi-material or light-metal car bodies and are often combined with adhesive bonding (Ref 7, 10). However, these processes reach their process limits, when the above mentioned ultra-high strength boron steels need to be joined.

In order to utilize the weight reduction potential of boron steels combined with aluminium alloys and thus enable further affordable weight reduction in mass vehicle production, suitable and cost-efficient mechanical joining technologies must be developed. This article introduces new developments for extending the process limits of three selected conventional mechanical joining methods and presents new promising approaches (Chapter 3), which combine thermal and mechanical joining principles. The last chapter shows the mechanical properties of the optimized joints, based on an exemplary material combination (6000 series aluminium alloy and 22MnB5 steel).

\section{Extending the Application Range of Established Mechanical Joining Technologies}

Mechanical joining methods have a long tradition in car body manufacturing. In the early days of the auto industry, different materials such as metals and wood were used. These were joined usually mainly by manual processes such as solid riveting and screwing. Later, vehicle generations were exclusively steel-based and mechanical joining methods were replaced by highly productive welding processes. Driven by the trend to utilize aluminium and other non-iron materials in car bodies, several innovations in the field of mechanical joining technologies were made during the last three decades. Most worth to mention are self-piece riveting (SPR) and clinching, which are standard processes in most car body manufacturing companies today (see Fig. 2a and b) (Ref 6, 7, 10)
The demand for special applications, lower cycle times, or more material and thickness flexibility lead to the development of new or improved mechanical joining technologies like flowdrill screwing and high-speed bolt joining for joints with onesided accessibility, e.g., in profile-intensive designs (Fig. 2c). These joining processes can be categorized as "joining by forming" (Ref 6). A common fundamental characteristic of joining by forming is the realization of positive and force fits by forming or punching at least one of the thin-walled parts to be joined (Ref 6). Consequentially follows that the application range of those joining methods is generally limited by the yield or tensile strength and/or the ductility of the part materials (Ref $6,11)$.

Steel sheet materials with tensile strengths of up to approx. $700 \mathrm{MPa}$ and a sufficient ductility of at least $8 \%$ can be clinched, clinch-bonded, and clinch-riveted with satisfying results regarding load capacity, as many recently published investigations on joining mild and high-strength steels show (Ref 12-15). With increasing tensile strengths and decreasing ductility, the formation of acceptable neck thicknesses and interlocks becomes more and more difficult (Ref 16, 17). The relatively high forming grades, which occur during the clinching process, can lead to local defects in the joint. Therefore, an adaption of the clinching tools is required (Ref 17). Busse et al. (Ref 11) present a new development to join boron steels with aluminium by a shear clinching process. The boron steel is pierced during the process and not formed and therefore requires relatively high process forces. Another possible solution to clinch low-ductile high-strength materials like boron steels with ductile materials such as typical automotive aluminium alloys is to use a punched or laser-cut pre-hole in the high-strength part. For good results, an exact concentric positioning of the pre-hole and the clinching tools is required. The exact positioning requires additional cycle time and positioning equipment. Therefore, processes which require pre-holes are only sub-optimal solutions for automotive series productions (Ref 7).

Semi-tubular self-pierce rivets need to spread in order to create the interlock with the die-sided part (see Fig. 2b, step No. 3). This limits the rivet material portfolio to steels with a certain ductility. At the same time, the rivet should not buckle or deform when piercing the punch-sided sheet. Based on this two requirements follows, that there also exists a limitation to the tensile strength of punch-sided materials joinable with SPR. For example, investigations from Mori et al. (Ref 18) on SPR of a steel with a tensile strength of $980 \mathrm{MPa}$ and an 5000 series aluminium alloy showed that even with an optimized die, the rivet's feets are strongly deformed and compressed. Currently, available rivets enable the joining of punch-sided steels up to $1000 \mathrm{MPa}$, while recent rivet developments in Germany allow joining even boron steels (Ref 7). However, the joinability of ultra-high-strength steels with semi-tubular SPRs is limited due to the joining principle.

High-speed bolt joining (also known as RIVTAC ${ }^{\circledR}$ technology), illustrated in Fig. 2c, is a relatively new process for car body manufacturing. The first series application was realized by DAIMLER in the Mercedes-Benz SL (R231) (Ref 19). An auxiliary joining element, comparable to a nail, is driven by a pneumatic-accelerated piston into the workpieces at speeds between 20 and $40 \mathrm{~m} / \mathrm{s}$. Mass inertia effects allow joining of even relatively thin-walled components without causing any significant global part deformation. In addition, the high deformation rates, in combination with friction between the 


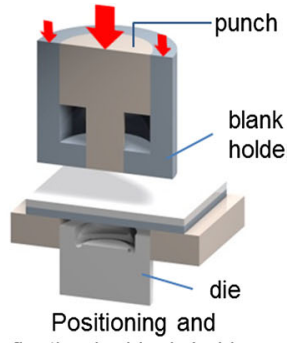

fixation by blank holder

(a)

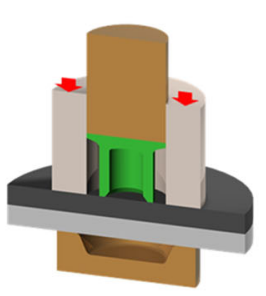

Fixation by blank holder

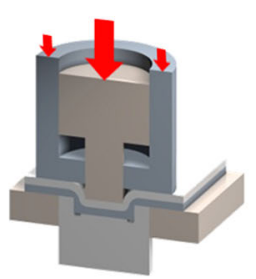

Forming in die

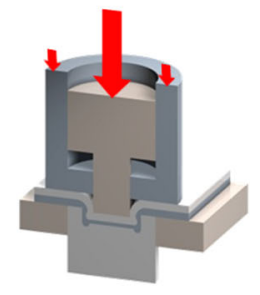

Forming of interlock

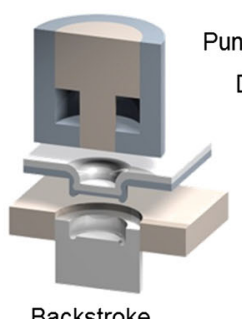

Backstroke

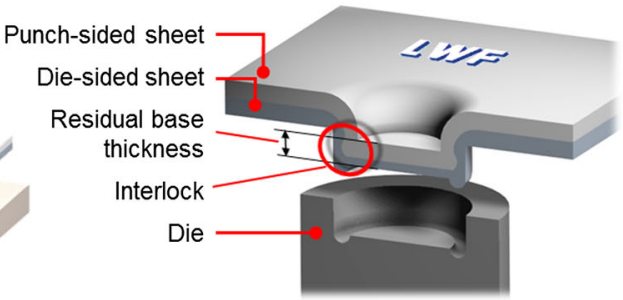

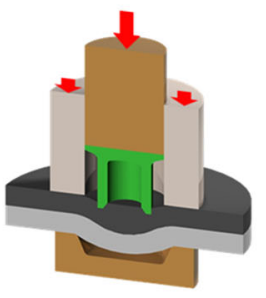

Punching of punch-sided part by rivet

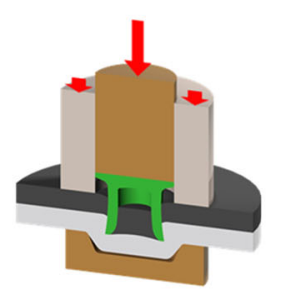

Upsetting / spreading of
rivet, forming of interlock

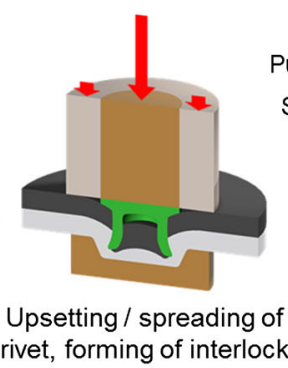

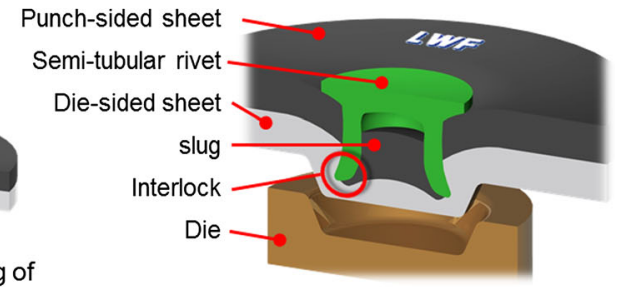

(b)
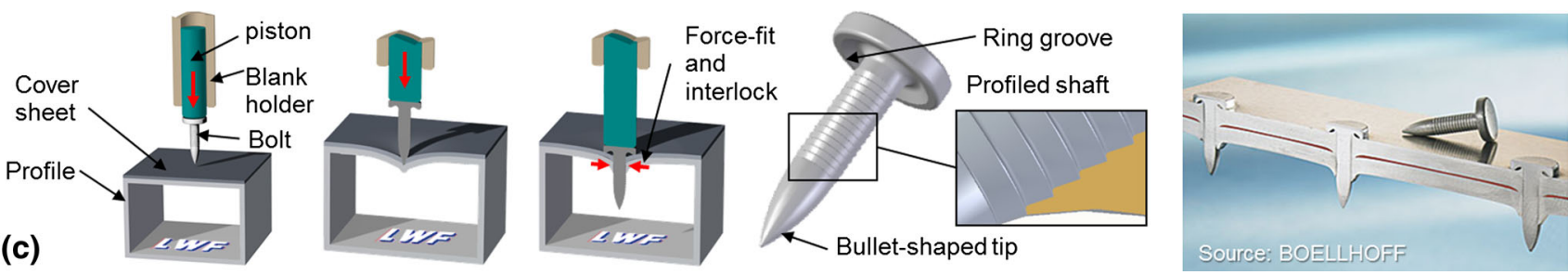

Fig. 2 Illustration of selected mechanical joining processes for automotive applications. (a) Clinching with static die (b) Self-pierce riveting (SPR) (c) High-speed bolt joining (Ref 7)

bolt and the workpieces, cause a quasi-adiabatic local temperature increase, improving the flow properties of the metal workpiece and also enabling the joining of high-strength materials (Ref 20). The bolt joint is a result of bolt anchoring in the base sheet, according to the principles of positive fit by the use of a profiled shaft. In addition, a force fit is achieved by an elastic deformation of the parts in the joining area, resulting in radial holding forces around the bolt. Similar to the semitubular self-pierce rivets, the tensile strength of the bolt material cannot be increased limitless. Due to the intense loads during joining process, micro-cracks can be initiated at the profiled shaft when using too brittle bolt material. These cracks result in very poor performance under fatigue loads (Ref 20). A comparable process principle called punch-nailing is presented by Wiethop et al. (Ref 21). In contrast the high-speed bolt shown in Fig. 2c, the punch-nail has a flat tip, which punches out a plug during joining process. This plug must be collected somehow after joining, what limits the application for punchnailing to joints with two-sided accessibility.

In order to demonstrate the process limitations of the above mentioned methods, Fig. 3a shows microsections of multi-material joints with a ductile micro-alloyed steel $(\mathrm{HC} 340+\mathrm{Z} 100)$, which mechanical properties are within the application range of the joining methods. In contrast to this, joining attempts with presshardened boron steel are displayed in Fig. 3b. As expected, the clinched sample failed by cracks in the boron part due to the low ductility of 22MnB5. The SPR joint failed by buckling of the rivet, due to the high strength of the boron steel. The bolt joint shows cracks around the formed hole (low ductility of 22MnB5) and a strongly deformed bolt tip (high-strength of 22MnB5). It is obvious, that without any modification, boron steels cannot be joined with these technologies. One possible solution to overcome the lack of suitable joining methods is a modification the mechanical properties of the brittle, martensitic boron steel

A recent, public-funded research project performed in a cooperation of three German research institutes investigated the potential of "local conditioning" of boron steels (Ref 22). In addition to the conventional hot-stamping process, a separate process step is required in order to enable the use of conventional mechanical joining processes in the subsequent assembly process (see Fig. 4).

During this process step, a short-cycle, controlled, and process-capable local heat treatment by induction or laser heating is performed. In order to preserve the crash-relevant part properties and to avoid global part deformation, the heat treatment is only applied locally to the areas where mechanical joining is necessary in the subsequent assembly process. Despite mechanical joining elements usually require only diameters from 3 to approx. $6 \mathrm{~mm}$, investigations were done with a conditioned area of $12 \mathrm{~mm}$ diameter in order to compensate the positioning tolerances of robot-integrated joining equipment in series production.

By annealing the martensite or by a controlled transformation of martensite to a mainly ferrite-perlite structure via 

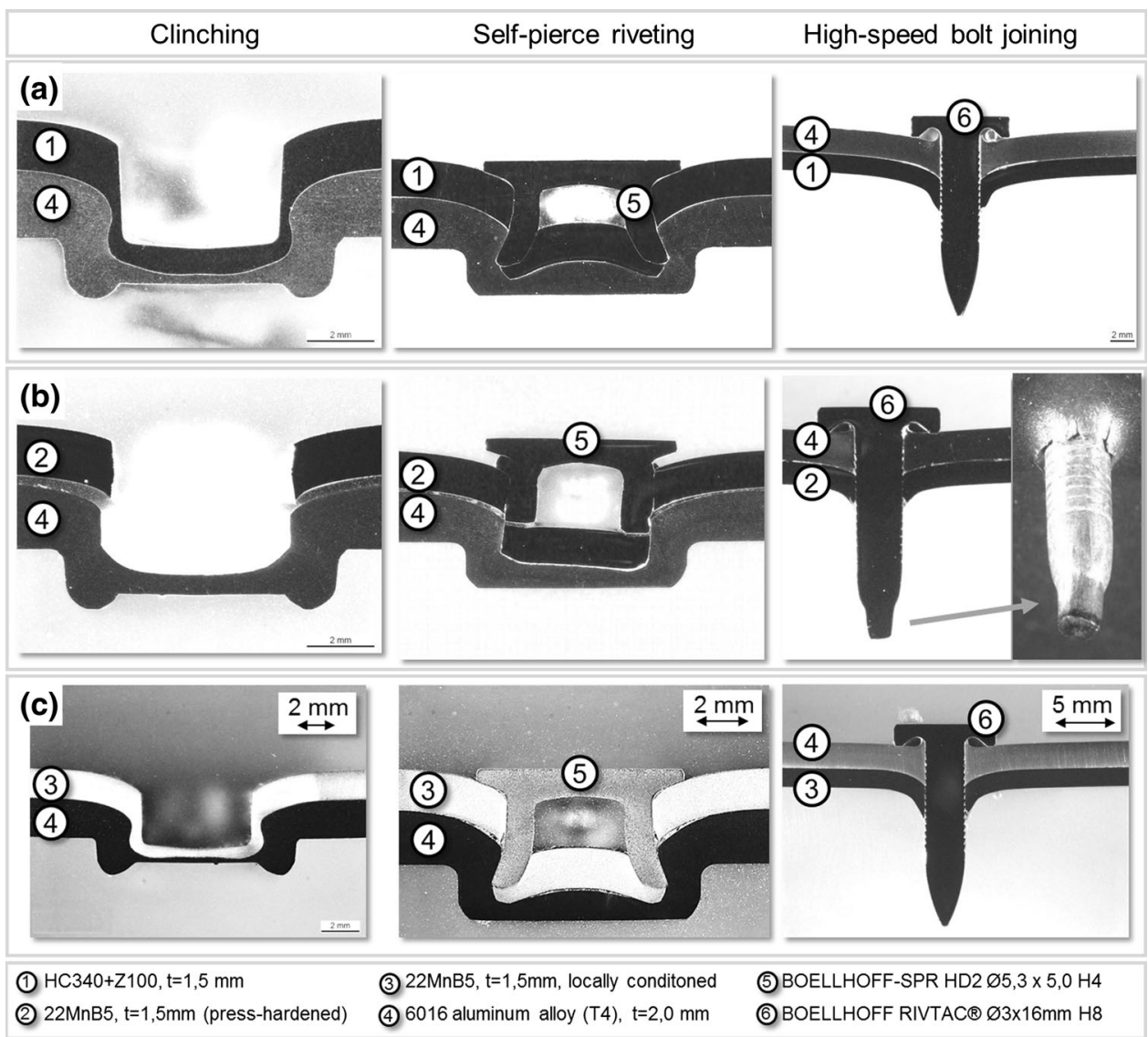

Fig. 3 Selected microsections of multi-material joints with varied steel grades. Microsections in (c) were etched
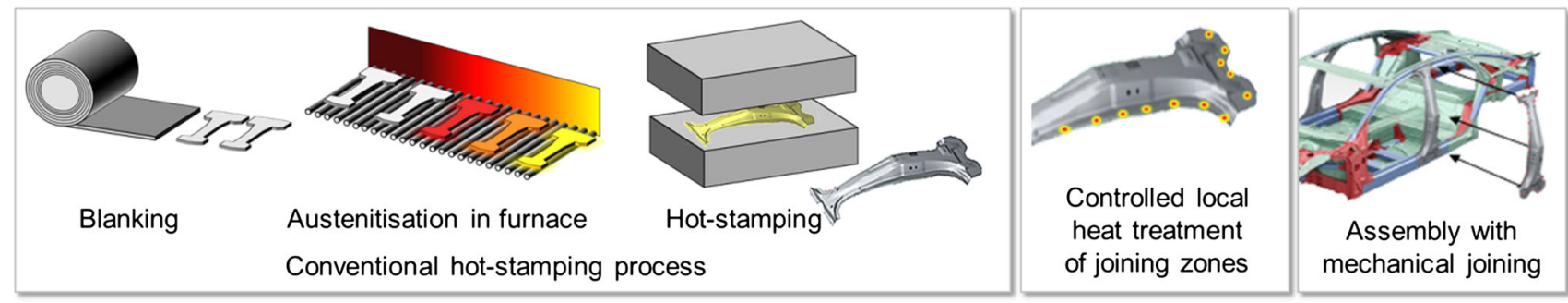

Fig. 4 Process concept for local conditioning of hot-stamped parts, enabling the application of conventional mechanical joining methods [illustration based on (Ref 25)]

different heat treatment profiles, the mechanical properties (tensile strength, hardness, ductility) of the joining zone can be adjusted to the individual process limits of the mechanical joining methods. Several temperature profiles with different cycle times were investigated. In contrast to already known principles of heat-assisted joining like presented in (Ref 23), the modification of mechanical properties is permanently. Therefore, the joining equipment does not contact materials with high temperatures and the lifetime of the joining tools can be increased. Another advantage is, that the part can be locally conditioned outside the car body assembly shop and handled and processed in subassemblies and later in the final assembly (Ref 22).

Exemplary results are shown in Fig. 5 and 6. It can be observed, that the microstructure can be transformed into more ductile microstructures like ferrite-perlite. Therewith, the hardness, tensile strength and yield strength can be reduced significantly in a defined area and elongation at crack can be increased. Investigations on the mechanical properties of the locally conditioned zone showed a tensile strength of approx. $650 \mathrm{MPa}$ and elongation at crack of about 25\% (Ref 22), enabling clinching. These properties required a local conditioning process time of $25 \mathrm{~s}$. Further investigations showed further process time reduction potential.

A much shorter temperature profile was applied, when the parts should be joined with self-pierce riveting or high-speed bolt joining, as these processes only require a slightly reduction of the hardness of the boron steel. This was be realized by annealing the martensite microstructure at $700{ }^{\circ} \mathrm{C}$ for $4 \mathrm{~s}$. The cycle time is within acceptable ranges for a series production. Figure $3 \mathrm{c}$ shows that the developed local conditioning process extends the application range of the above mentioned 


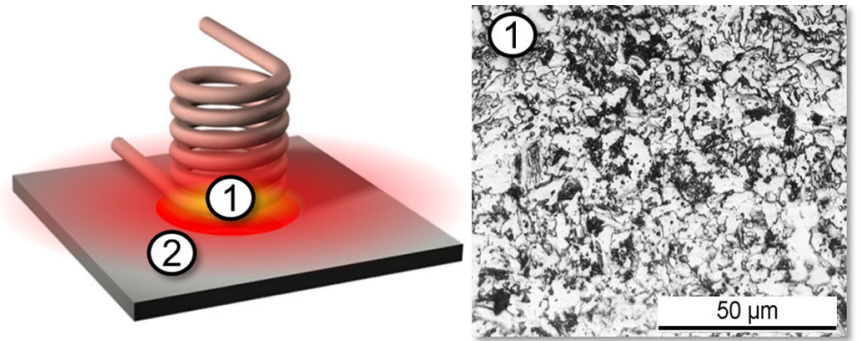

Illustration of local conditioning by inductive heating ocally conditioned area:

Mainly ferrite-perlite

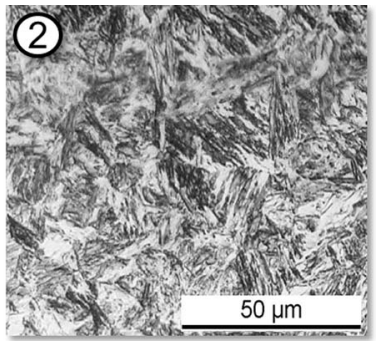

Surrounding area: Martensite

Fig. 5 Microstructure of press-hardened 22MnB5 steel after local conditioning process (Ref 22)

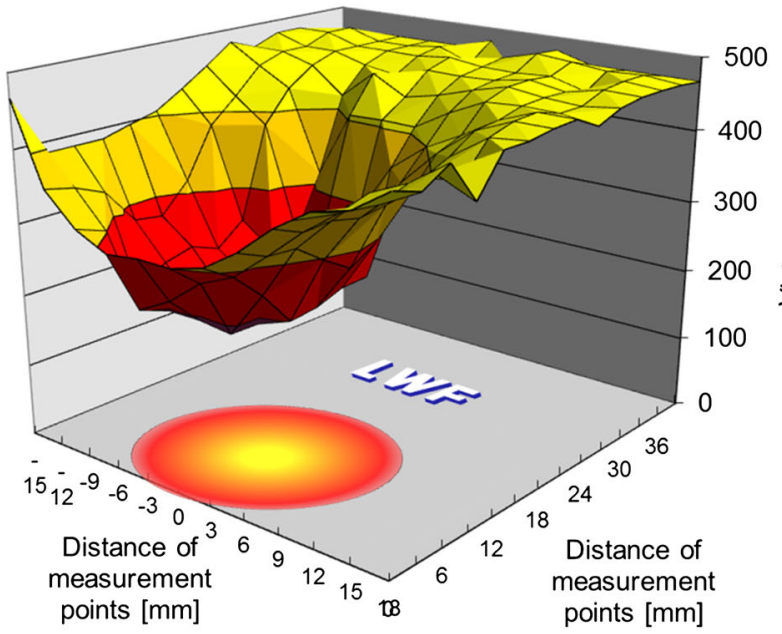

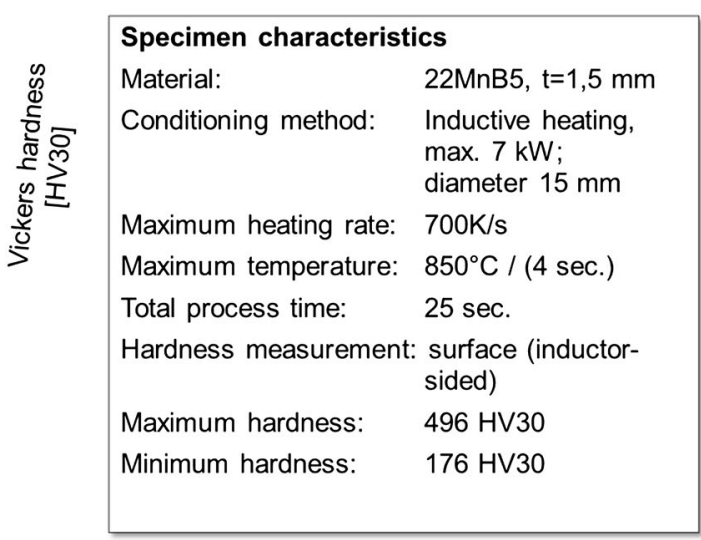

Fig. 6 Illustration of measurement results of a Vickers hardness scan on surface after local conditioning (Ref 22)

mechanical joining technologies to ultra-high-strength boron steels. In Chapter 4, selected results on mechanical testing under tensile shear loads of the joints are shown.

\section{Development of New Joining Technologies for Joining UHSS to Aluminium}

Another option to solve the challenges when joining boron steels with aluminium is the development of new joining principles. Figure 7 shows the process steps of three selected methods.

Figure $7 \mathrm{a}$ shows a self-pierce riveting process with solid rivets. As illustrated, the joint is based mainly on a positive lock created by forming the die-sided aluminium sheet into a ring groove at the rivet (Ref 25). In addition, force fits between the joined sheets and rivet shaft as well as an axial force caused by axial tensile stress in the rivet (transmitted by countersunk head to the joined parts) can be observed. In contrast to the classic SPR process with semi-hollow rivets, the solid rivet is not formed in order to create interlock. As already explained above, this allows the use of ultra-high-strength materials for the rivet (Ref 7, 24, 25). There are different rivet types with more than one ring groove available ( $\operatorname{Ref} 25)$.
Very promising approaches for joining low-ductile and highstrength materials in multi-material joints are the so-called thermal-mechanical joining processes (Ref 7). These processes are based on an intelligent combination of thermal and mechanical joining principles (Ref 26-28). In addition, these processes can be combined with adhesive bonding (Ref 28-30).

Figure $7 \mathrm{~b}$ shows the resistance element welding (REW) process. Figure 7c shows the friction element welding (FEW) process. Miles et al. (Ref 26) present a comparable process called friction bit welding. A common characteristic of these processes is the use of an auxiliary joining element made of steel, which is joined by RSW or friction welding with the boron steel part, while the non-ferrous cover sheet is joined with a positive and a force lock to the auxiliary element (Ref 7). The use of an additional steel joining element allows evading the welding incompatibility of dissimilar material joints (Ref 28). As there is no forming or punching of the boron steel sheet required, these processes are highly suitable for all kind of advanced high-strength steels with relatively low ductility, for instance martensitic steels with tensile strength of more than $1800 \mathrm{MPa}$ (Ref 30). Nevertheless, the occurring process temperatures have an effect on the microstructure in the joining zone, comparable with the effects when applying classic RSW. The heat-affected zones can be observed on etched microsections, displayed in Fig. $8 \mathrm{~b}$ and c. 


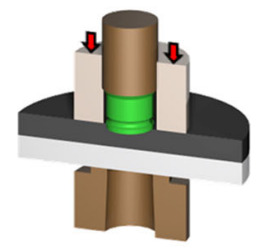

(a)

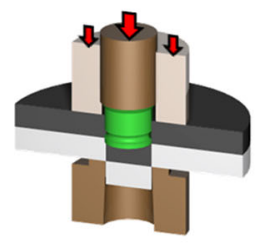

Punching of both parts by rivet

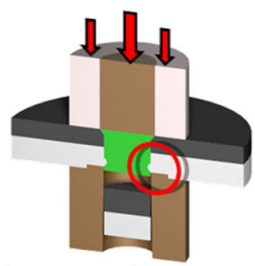

Increase of process force, forming of interlock

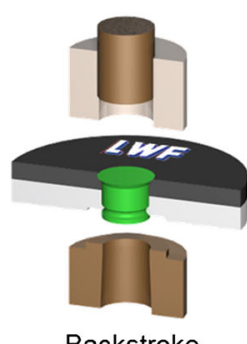

Backstroke
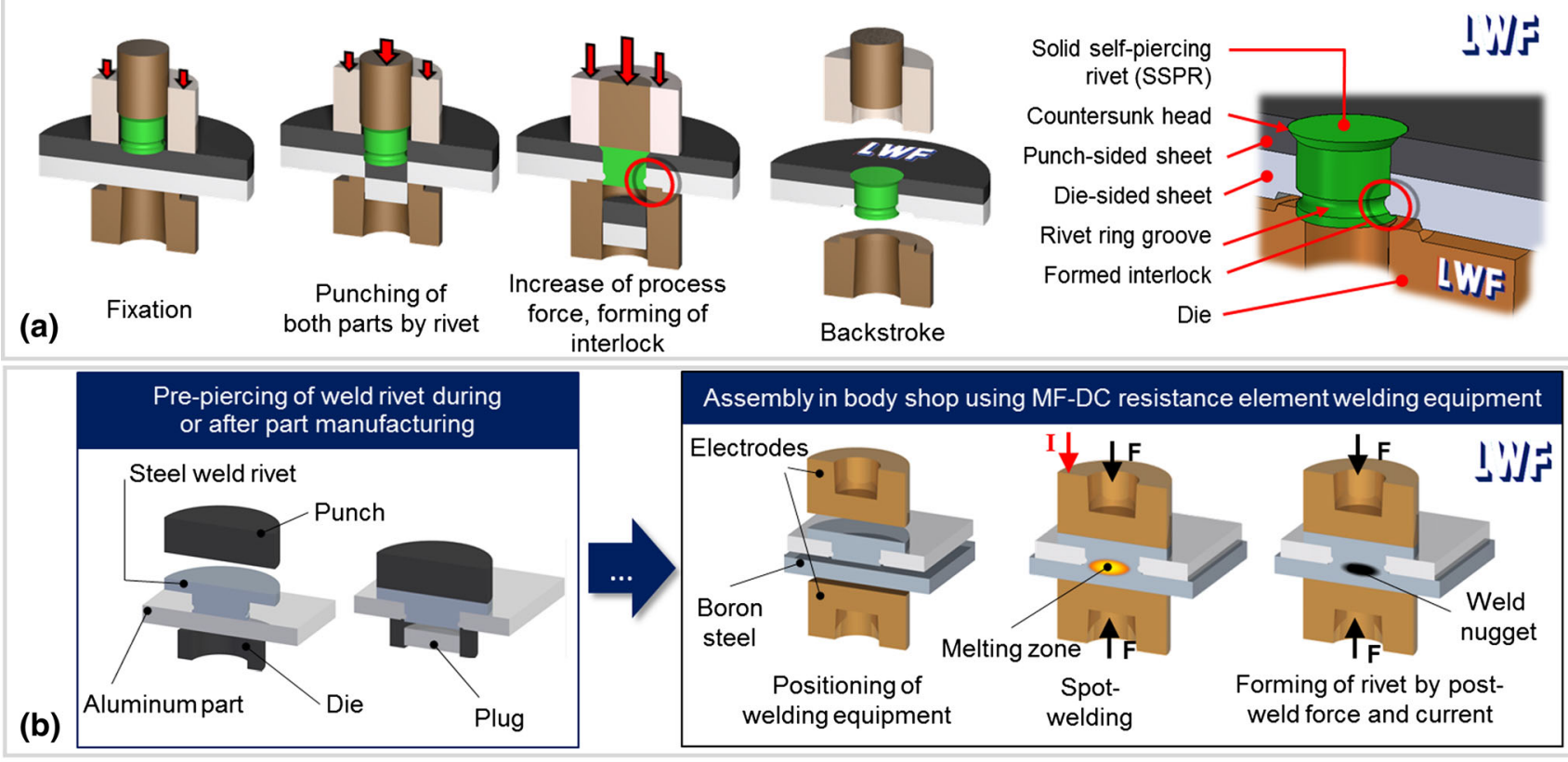

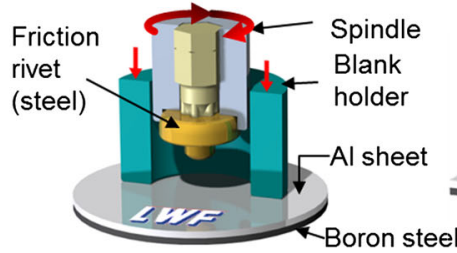
(c)
Positioning of blank holder and acceleration of spindle

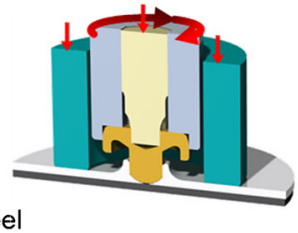

Plastification of cover material an start of friction welding phase

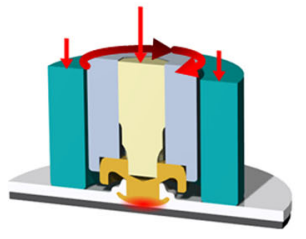

Friction welding process, shortening of rivet

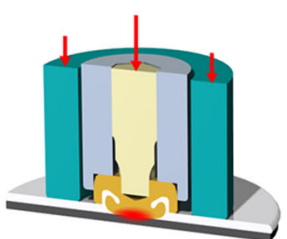

Stop of spindle, press-welding

Fig. 7 Illustration of selected innovative joining methods for UHSS-aluminium combinations. (a) Self-pierce riveting with solid rivets (SSPR); (b) Resistance element welding (REW); (c) Friction element welding (FEW) (Ref 7)

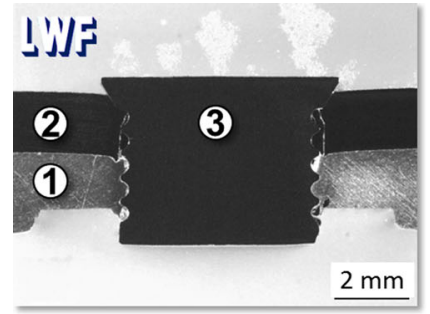

(a)

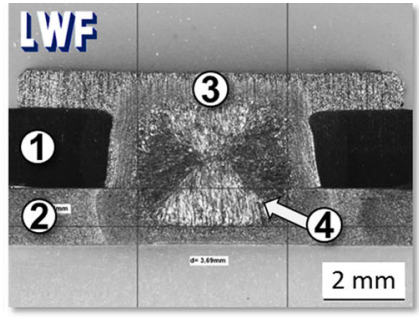

(b)

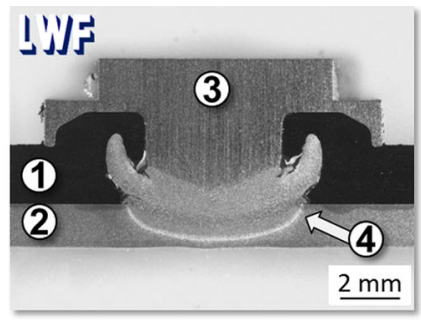

(c)
(1) $6 x x x$ aluminium alloy, $\mathrm{t}=2,0 \mathrm{~mm}$

(2) $22 \mathrm{MnB} 5, \mathrm{t}=1,5 \mathrm{~mm}$

(3) Auxiliary joining element

(4) Heat affected zone

Fig. 8 Etched microsections of aluminium-to-boron-steel joints. (a) Self-pierce riveting with solid high-strength rivets; (b) Resistance element welding; (c) Friction element welding (Ref 30)

\section{Comparison of Load-Bearing Capability}

In order to measure and optimize the performance of the joining methods, experimental destructive testing is one of the most common methods. Within this article, exemplary results from lap-shear tensile tests are shown.

The specimen parts have the dimension $45 \times 105 \mathrm{~mm}^{2}$ with an overlapping length of $16 \mathrm{~mm}$, according to the German standard DVS/EFB 3480-1, which is the established standard for testing of mechanical joints for automotive car body structures in Germany (Ref 31). The multi-material joints used a heat-treatable aluminium alloy (AA6016) with a sheet thickness of $2.0 \mathrm{~mm}$ and a boron steel (22MnB5) with a sheet thickness of $1.5 \mathrm{~mm}$. The press-hardened boron steel was conditioned locally for joints produced by clinching, by selfpierce riveting with semi-hollow rivets (SPR) and by highspeed bolt joining $\left(\right.$ RIVTAC $\left.^{\circledR}\right)$. The boron steel was not conditioned for self-pierce riveting with solid rivets (SSPR), for $\mathrm{REW}$, for FEW and for adhesive bonding. The produced specimen were heat-treated at $180{ }^{\circ} \mathrm{C}$ for $30 \mathrm{~min}$ in an electric furnace in order to simulate the automotive cataphoresic paint bake process, which leads to an aging and increase of 


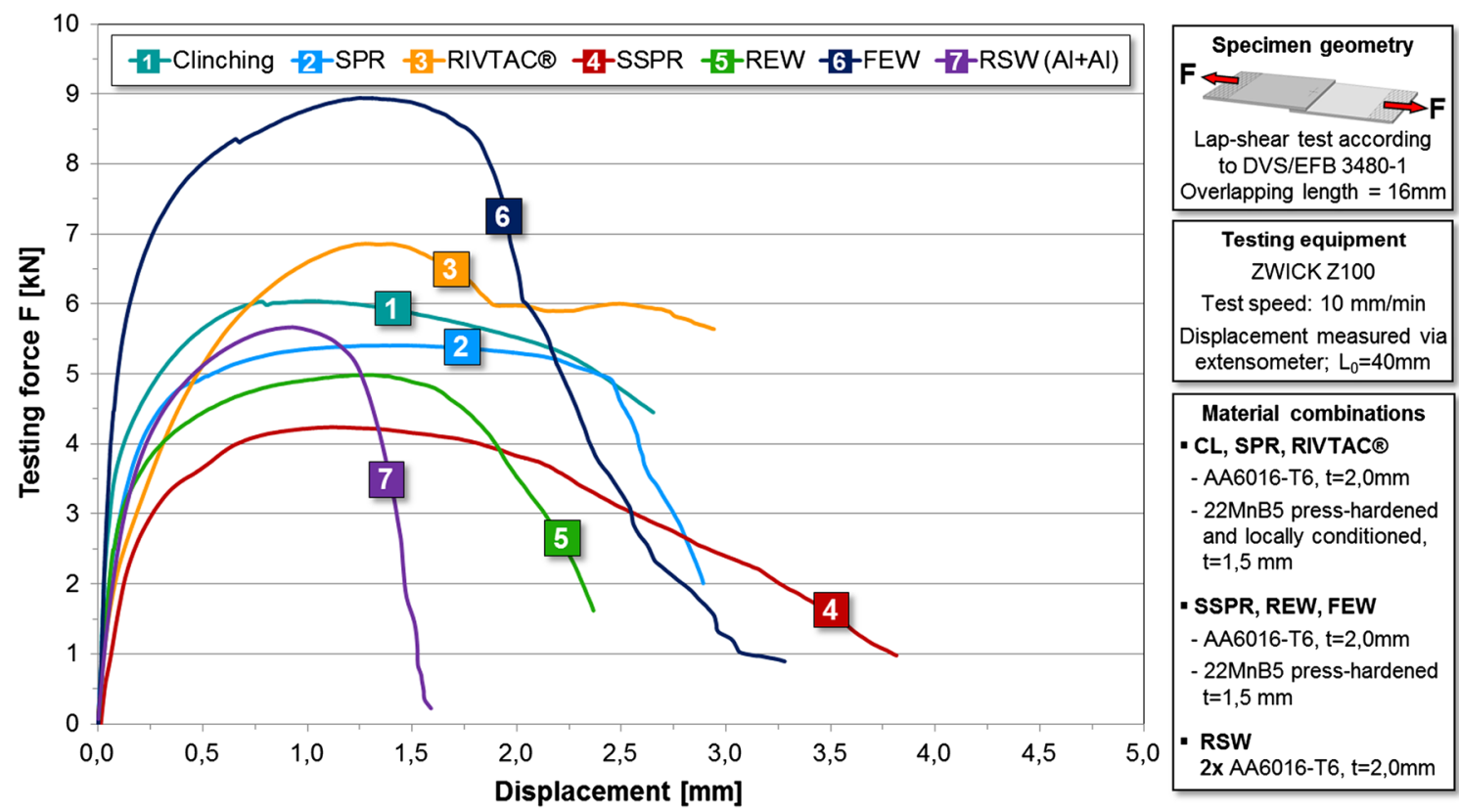

Fig. 9 Exemplary force-displacement plots of tested lap-shear specimens joined with different technologies

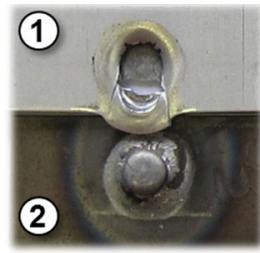

Local conditioning + clinching

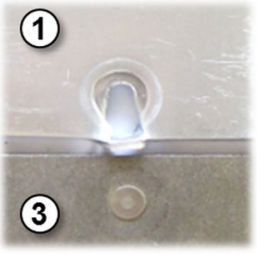

Self-pierce riveting with solid rivets

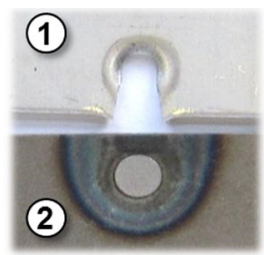

Local conditioning + Local conditioning

self-pierce riveting with + RIVTAC $₫$ semi-hollow rivets

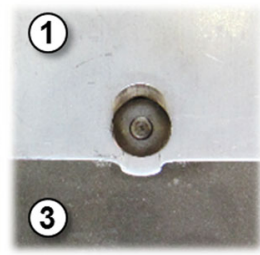

Resistance element welding
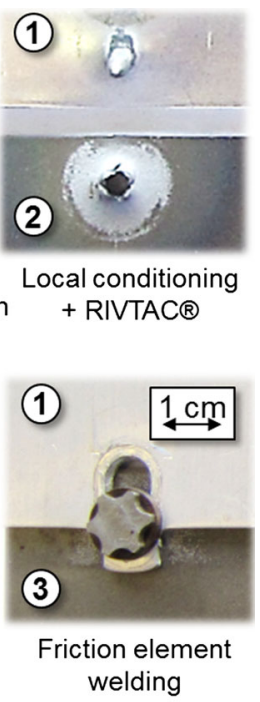

(1) AA6016-T4, $\mathrm{t}=2,0 \mathrm{~mm}$

(2) $22 \mathrm{MnB} 5$ (local conditioned) $\mathrm{t}=1,5 \mathrm{~mm}$

(3) $22 \mathrm{MnB} 5$, press-hardened, $t=1,5 \mathrm{~mm}$

Fig. 10 Failure modes of different joints after lap-shear test

mechanical properties of the 6000 series aluminium. Five specimens per joining method were tested at a speed of $10 \mathrm{~mm}$ per minute, while the displacement was measured locally on the specimens with an extensometer. In addition five specimens created by RSW of two aluminium alloy specimen parts, were tested for reference reasons.

A representative force-displacement plot for each joining technology is displayed in Fig. 9. Except for the RIVTAC ${ }^{\circledR}$ specimen, a failure in the aluminium part can be observed (see Fig. 10). Therefore the maximum shear load is limited by the aluminium part, not by the joining elements. The differences in maximum shear load result in the different diameters of the auxiliary elements and joining-process-related effects. From the displayed plots, the maximum testing force of $8.94 \mathrm{kN}$ was achieved from a friction-element-welded specimen. The reason for this is the aluminium material, which is displaced and collected in the ring groove under the joining element's head during the joining process (see Fig. 8c). This local increase of sheet thickness results in higher maximum shear loads.

As discussed during the introduction, adhesive bonding, combined with a punctual mechanical or thermal-mechanical joining process is highly suitable for multi-material joints (hybrid joining). Figure 11 shows results of both elementary and hybrid-joined lap-shear specimen. The adhesive used is an automotive-typical heat-curing high-strength $1 \mathrm{~K}$ epoxy (DOW BETAMATE $^{\mathrm{TM}} 1496 \mathrm{~V}$ ) [see also (Ref 10)]. After application of the adhesive to the parts, the specific punctual joining method was applied. Subsequently, the adhesive was cured in a furnace at $180{ }^{\circ} \mathrm{C}$ for $30 \mathrm{~min}$, what corresponds with the typical paint bake process in automotive production after electrophoretic coating of the car body. For reference reasons, bonded-only specimens (without punctual joint) were tested as well. It can be observed, that the maximum forces could be increased significantly, compared to the elementary joints (see Figs. 11, 12).

The highest mean maximum force of $19.59 \mathrm{kN}$ is achieved by the adhesive-bonded-only specimens. The punctual joining methods reduce the size of the effective load-transmitting adhesive layer area resulting in a lower maximum shear load, what is also characteristic for hybrid joints (Ref 7). The difference in maximum force of the hybrid joints results from the different influences on the adhesive layer. Heat-intensive processes, like RSW or the thermal-mechanical methods, burn a certain area of the adhesive layer, while mechanical joining processes squeeze out the adhesive due to high processes forces. It is worth to mention here, that the presence of uncured adhesive also can have negative effects on the formation of mechanical joints, e.g., by filling interlock areas and therewith 


\begin{tabular}{|c|c|c|c|c|}
\hline Specimen geometry & Testing equipment & Materials & Adhesive & Displayed information \\
\hline 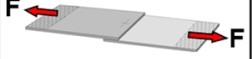 & $\begin{array}{c}\text { ZWICK Z100 } \\
\text { Test speed: } 10 \mathrm{~mm} / \mathrm{min}\end{array}$ & $\begin{array}{l}\text { - AA6016-T6, } \mathrm{t}=2,0 \mathrm{~mm} \\
\text { - } 22 \mathrm{MnB} 5 \text { press-hardened, } \mathrm{t}=1,5 \mathrm{~mm}\end{array}$ & \begin{tabular}{|c|} 
DOW \\
BETAMATE $^{\text {TM }} 1496 \mathrm{~V}$
\end{tabular} & $\begin{array}{l}\text { lard } \\
\text { tion }(\sigma)\end{array}$ \\
\hline $\begin{array}{l}\text { Lap-shear test } \\
\text { according } \\
\text { to DVS/EFB 3480-1 } \\
\text { Overlapping } \\
\text { length }=16 \mathrm{~mm}\end{array}$ & $\begin{array}{l}\text { Displacement } \\
\text { measured via } \\
\text { extensometer; } \\
\mathrm{L}_{0}=40 \mathrm{~mm}\end{array}$ & $\begin{array}{l}\text { (SSPR, REW, FEW, Adhesive- } \\
\text { bonding-only) } \\
\text { - } 22 \text { MnB5 press-hardened and locally } \\
\text { conditioned, t=1,5 mm (Clinching, } \\
\text { SPR, RIVTAC@) }\end{array}$ & \begin{tabular}{|} 
Layer thickness $0,3 \mathrm{~mm}$ \\
Curing conditions \\
$180^{\circ} \mathrm{C}, 30 \mathrm{~min}$. \\
(electric furnace)
\end{tabular} & $\begin{array}{ll} & \text { Mean value }(\bar{x}) \\
& \text { Number of } \\
\text { specimen } n=5\end{array}$ \\
\hline
\end{tabular}

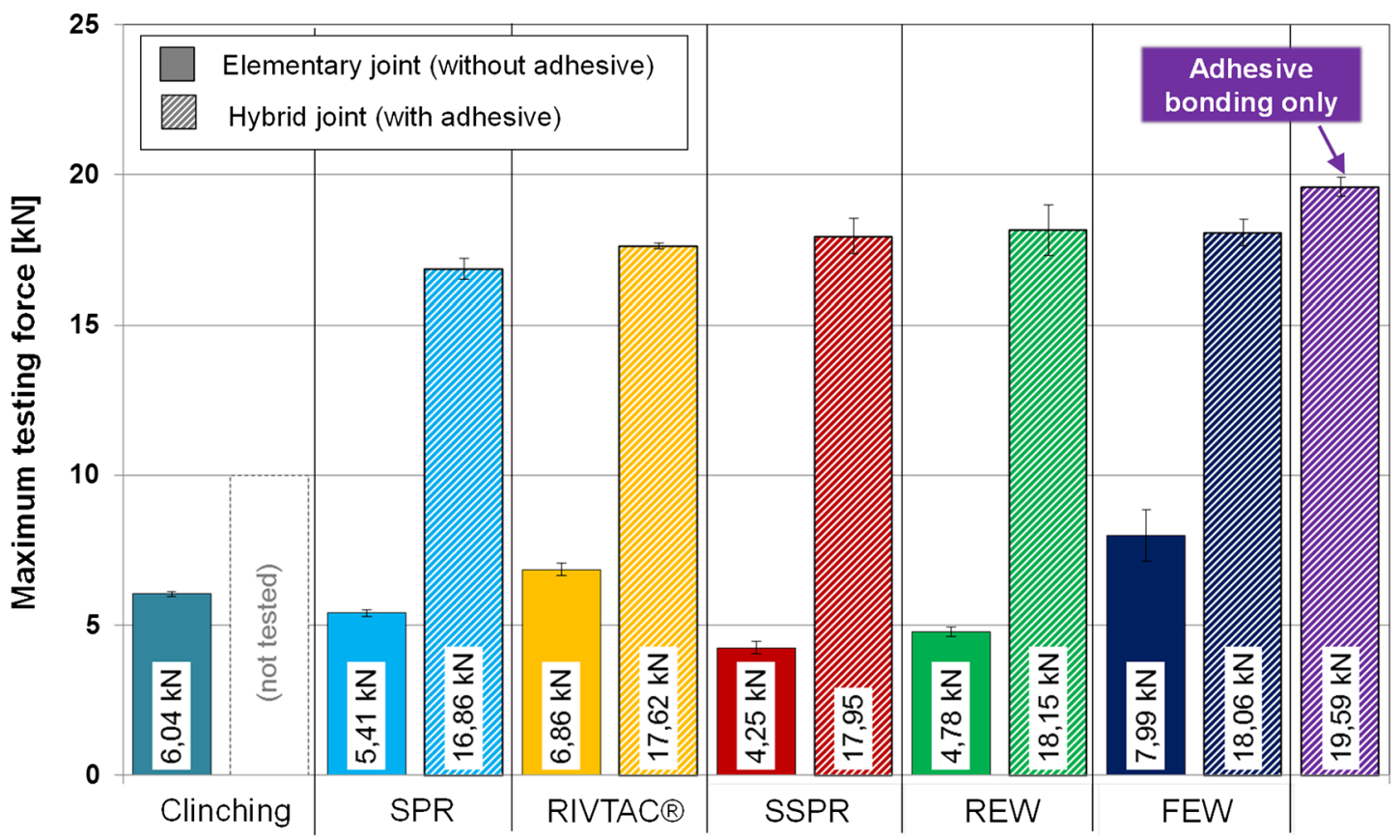

Fig. 11 Comparison of mean maximum force under shear tensile load for elementary and hybrid joints made of AA6016 and 22MnB5 with different joining techniques

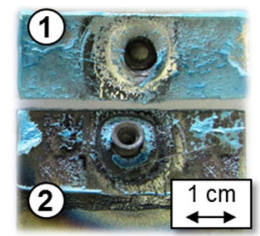

Local conditioning + self-pierce riveting with semi-hollow rivets + adhesive bonding

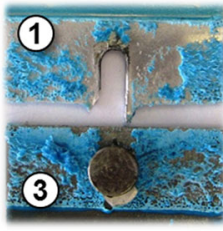

Resistance element welding + adhesive bonding

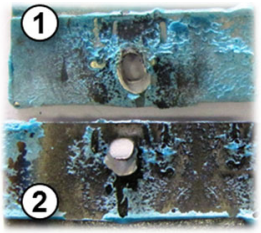

Local conditioning

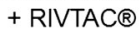
+ adhesive bonding

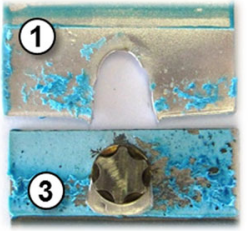

Friction element welding + adhesive bonding

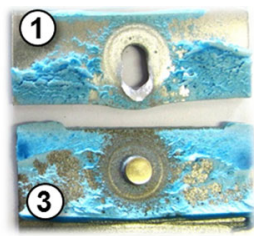

Self-pierce riveting with solid rivets + adhesive bonding

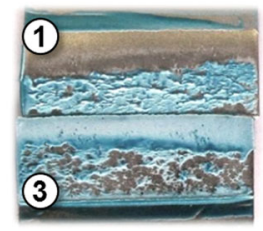

Adhesive bonding (external fixation during curing)
(1) AA6016-T4, $\mathrm{t}=2,0 \mathrm{~mm}$

(2) $22 \mathrm{MnB} 5$ (local conditioned) $\mathrm{t}=1,5 \mathrm{~mm}$

(3) $22 \mathrm{MnB} 5$, press-hardened, $\mathrm{t}=1,5 \mathrm{~mm}$

Fig. 12 Failure modes of different (hybrid) joints after lap-shear test

inhibiting the accurate forming of the joint (Ref 7, 27). Therefore, the development of punctual and hybrid joining technologies is complex.
Several other tests were performed, e.g., under high strain rates and peel loads. One goal of these investigations was to verify, if joints would fail through cracks in the heat-affected zones caused by the local conditioning of the boron steels. As the failure always occurred in the aluminium part or the joining element, the local conditioning technology proved to be applicable for joints in crash-critical areas of a vehicle (Ref 25).

\section{Summary and Conclusions}

Cost-efficient joining technology is the key to the realization of innovative lightweight car bodies in multi-material design. Increasing material diversity, as well as increasing demand for process reliability, flexibility and cost-efficiency result in a high level of innovation pressure in the field of joining technology.

In general, it can be summarized, that classic mechanical joining combined with local conditioning as well as the presented new approaches show sufficient load-bearing capabilities for automotive applications. As all of these methods have individual advantages and disadvantages, a general recommendation for one technology is not possible. The decision to apply one or more technologies for a series production depends on the boundaries (e.g., production volume, required strength, material flexibility, costs). However, further development steps are necessary to reach maturity for series application. 
The continuous development and qualification of new joining technology processes represents an important contribution to the realization of future mobility. The Laboratory of Materials and Joining Technology (LWF) at the University of Paderborn, Germany successfully works together with industry and science since 1976 in this field.

\section{Acknowledgments}

In this article, some selected results from a public-funded research projects were presented. The authors thank the research association for Steel application-Forschungsvereinigung Stahlanwendung e.V.-FOSTA, Duesseldorf and the European Association of Sheet Metal Working (EFB), Hanover, as well as the German Federal Ministry of Economics and Technology (BMWi) and the German Federation of Industrial Research Associations (AiF) for their organizational and financial support of applicationoriented industrial collaborative research.

\section{References}

1. T. Gänsicke and M. Goede, The Technical Motivation for Lightweight Design (in German), Leichtbau in der Fahrzeugtechnik, H. Friedrich. Springer Vieweg Verlag, Wiesbaden, Germany, 2013, p 31-42. ISBN 978-3-8348-1467-8

2. H. Friedrich, P. Treffinger, G. Kopp, H. Knäbel, Materials and Designs Enable New Car Concepts. (in German). Forschung für das Auto von Morgen, V. Schindler and I. Sievers, Springer Verlag, Berlin, Germany, 2008, p 301-347. ISBN 978-3-540-74150-3

3. M. Merklein, J. Lechler, and T. Stoehr, Investigations on the Thermal Behaviour of Ultra High Strength Boron Manganese Steels Within Hot Stamping, Int. J. Mater: Form., 2009, 2(1 Supplement), p 259-262

4. M. Lai and R. Brun, Latest Developments in Sheet Metal Forming Technology and Materials for Automotive Application: The Use of Ultra High Strength Steels at Fiat to Reach Weight Reduction at Sustainable Costs, Key Eng. Mater., 2007, 344, p 1-8

5. Boellhoff Group, N.N. Fourth Generation Joins in the 4th Dimension. Boellhoff Press Release, May 26 2010; Image source: Porsche AG. http://www.boellhoff.de/de/de/unternehmen/news-presse/pressemitteilun gen/2010/porsche-panamera.php

6. P. Groche, S. Wohletz, M. Brenneis, C. Pabst, and F. Resch, Joining by Forming-A Review on Joint Mechanisms, Applications and Future Trends, J. Mater. Process. Technol., 2014, 214, p 1062-1093

7. O. Hahn, G. Meschut, S. Suellentrop, V. Janzen and T. Olfermann, Joining Technologies in Hybrid Lightweight Structures (in German), Leichtbau der Fahrzeugtechnik, H. Friedrich, Springer Vieweg Verlag, Wiesbaden, Germany, 2013, p 622-662

8. D. Schmid, C. Neudel, M.F. Zäh, and M. Merklein, Press-Welding of Aluminium-Steel-Joints (in German), Lightweight Design, Vol 5(1), Jan 2012, Springer, Wiesbaden, Germany (ISSN: 1865-4819), p 14-19

9. J. Bruckner and G. Trommer, Arc Joining of Steel and Aluminium (in German), Lightweight Design, Vol 5(4), April 2012, Springer, Wiesbaden, Germany (ISSN: 1865-4819), p 52-56

10. B. Bartczak, J. Mucha, and T. Trezepiecínski, Stress Distribution in Adhesively Bonded Joints and the Loading Capacity of Hybrid Joints of Car Body Steels for the Automotive Industry, Int. J. Adhesion Adhesives, 2013, 45, p 42-52

11. S. Busse, M. Merklein, K. Roll, M. Zürn, and H. Schubert, Numerical and Experimental Investigations of an Innovative Clinching Process. Proceedings of the 10th International Conference on Technology of Plasticity (ICTP), Düsseldorf, 2011, p 736-741

12. J. Mucha, The Analysis of Lock Forming Mechanism in the Clinching Joint, Mater. Des. Issue, 2011, 32, p 4943-4954
13. J. Mucha and W. Witkowski, The Experimental Analysis of the Double Joint Type Change Effect on the Joint Destruction Process in Uniaxial Shearing Test, J. Thin-Walled Struct., 2013, 66, p 39-49

14. X. He, L. Zaho, H. Yang, B. Xing, Y. Wang, C. Deng, F. Gu, and A. Ball, Investigations of Strength and Energy Absorption of Clinched Joints, Computational Materials Science, 2014. doi:10.1016/j.commat sci.2014.01.056

15. J. Mucha, L. Kascak, and E. Spisak, The Experimental Analysis of Forming and Strength of Clinch Riveting Sheet Metal Joint Made of Different Materials, Advances in Mechanical Engineering, Vol 2013, ID848973

16. C.-J. Lee, J.-Y. Kim, S.-K. Lee, D.-C. Ko, and B.-M. Kim, Parametric Study on Mechanical Clinching Process for Joining Aluminium Alloy and High-Strength Steel Sheets, J. Mech. Sci. Technol., 2010, 24, p 123-126

17. Y. Abe, K. Mori, and T. Kato, Joining of High Strength Steel and Aluminium Alloy Sheets by Mechanical Clinching with Dies for Control of Metal Flow, J. Mater. Process. Technol., 2012, 212, p 884-889

18. K. Mori, T. Kato, Y. Abe, and Y. Ravshanbek, Plastic Joining of Ultra High Strength Steel and Aluminium Alloy Sheets by Self Piercing Rivet, CIRP Ann. Manuf. Technol., 2010, 55(1), p 283-286

19. H. Schubert and M. Moehring, Flexible material joining technology for tomorrow's innovative lightweight design. Proceedings to Conference Joining in Car Body Engineering 2012, Automotive Circle International/ Vincentz Network Hannover, Bad Nauheim, Germany, 18 April 2012

20. T. Draht, Joining in the automotive industry-one-sided joining without pre-hole (in German), Lightweight Design, Vol 1(6), Dec 2008; Springer, Wiesbaden, Germany (ISSN: 1865-4819), p 20-23

21. M. Dreher, U. Füssel, V. Johne, J. Amedick, and P. Wiehtop, PunchNailing-Mechanical Joining of High Strength Sheet Materials, Lightweight Design, Vol 2(3), June 2009, Springer, Wiesbaden, Germany (ISSN: 1865-4819), p 48-51

22. W.-G. Drossel, M. Ahnert, E. Broschwitz, C. Kraus, H.-J. Maier, F.-W. Bach, W. Reimche, C. Birr, G. Meschut, O. Hahn, M. Matzke, and I. Olfermann, Local Conditioning of Press-Hardened Steel for Hybrid Joining of Multi-Material Structures (in German), Proceedings to Conference 3. Fügetechnisches Gemeinschaftskolloquium 2013 Rostock, Germany, Dec 2013. Tagungsband T 37, EFB Hannover 2013, ISBN 978-3-86776-415-5, p 10-11

23. Y. Durandet, R. Deam, A. Beer, W. Song, and S. Blacket, Laser Assisted Self-Pierce Riveting of AZ31 Magnesium Alloy Strips, Mater. Des., 2010, 31, p 13-16

24. J. Mucha, The Effect of Material Properties and Joining Process Parameters on Behaviour of Self-Pierce Riveting Joints Made with the Solid Rivet, J. Mater. Des., 2013, 52, p 932-946

25. J. Mucha, The Numerical Analysis of the Effect of the Joining Process Parameters on Self-Piercing Riveting Using the Solid Rivet, Arch. Civ. Mech. Eng., 2013. doi:10.1016/j.acme.2013.11.002

26. M. Miles, S.-T. Hong, C. Woodward, and Y.-H. Jeong, Spot Welding of Aluminium and Cast Iron by Friction Bit Joining, Int. J. Precis. Eng. Manuf., 2013, 14(6), p 1003-1006

27. Y. Li, Z. Wei, Z. Wang, and Y. Li, Friction Self-Piercing Riveting of Aluminium Alloy AA6061-T6 to Magnesium Alloy AZ31B, J. Manuf. Sci. Eng., 2013, 135(6), p 061007

28. G. Meschut, O. Hahn, T. Olfermann, and V. Janzen, Innovative Joining Technologies for Multi-Material Structures, Weld. World, 2014, 58(1), p 65-75

29. M. Maiwald and J. Thiem, Joining Without Pre-Hole by Friction Element Welding (in German), ATZ production, Issue 02-2012, Springer/Vieweg Fachmedien, Wiesbaden, Germany, 2012, p 92-99

30. G. Meschut, V. Janzen, M. Matzke, and T. Olfermann, Comparison of Innovative Thermal Joining Technologies for Joining Ultra-HighStrength Steels in Multi-Material Structures (in German), DVSBerichte, Band 296. DVS Media GmbH, Düsseldorf, Germany, 2013. ISBN: 978-3-87155-614-2

31. DVS/EFB 3480-1, Testing of Joint Properties-Testing of Joints Produced by Mechanical Joining Combined with Adhesive Bonding (in German), Fachbuchreihe Schweißtechnik Band 153 Taschenbuch DVS-Merkblätter und -Richtlinien Mechanisches Fügen. DVS Media GmbH, Düsseldorf, Germany, 2007, ISBN: 978-3-87155-230-4 